\title{
GYNECOLOGY
}

\section{A model to predict risk of blood transfusion after gynecologic surgery}

\author{
Jamie Stanhiser, MD; Kevin Chagin, MS; J. Eric Jelovsek, MD, MMEd
}

BACKGROUND: A model that predicts a patient's risk of receiving a blood transfusion may facilitate selective preoperative testing and more efficient perioperative blood management utilization.

OBJECTIVE: We sought to construct and validate a model that predicts a patient's risk of receiving a blood transfusion after gynecologic surgery. STUDY DESIGN: In all, 18,319 women who underwent gynecologic surgery at 10 institutions in a single health system by 116 surgeons from January 2010 through June 2014 were analyzed. The data set was split into a model training cohort of 12,219 surgeries performed from January 2010 through December 2012 and a separate validation cohort of 6100 surgeries performed from January 2013 through June 2014. In all, 47 candidate risk factors for transfusion were collected. Multiple logistic models were fit onto the training cohort to predict transfusion within 30 days of surgery. Variables were removed using stepwise backward reduction to find the best parsimonious model. Model discrimination was measured using the concordance index. The model was internally validated using 1000 bootstrapped samples and temporally validated by testing the model's performance in the validation cohort. Calibration and decision curves were plotted to inform clinicians about the accuracy of predicted probabilities and whether the model adds clinical benefit when making decisions.

RESULTS: The transfusion rate in the training cohort was $2 \%$ (95\% confidence interval, 1.72-2.22). The model had excellent discrimination and calibration during internal validation (bias-corrected concordance index, 0.906; 95\% confidence interval, 0.890-0.928) and maintained accuracy during temporal validation using the separate validation cohort (concordance index, 0.915; 95\% confidence interval, 0.872-0.954). Calibration curves demonstrated the model was accurate up to $40 \%$ then it began to overpredict risk. The model provides superior net benefit when clinical decision thresholds are between $0-50 \%$ predicted risk.

CONCLUSION: This model accurately predicts a patient's risk of transfusion after gynecologic surgery facilitating selective preoperative testing and more efficient perioperative blood management utilization.

Key words: blood management, blood transfusion, blood transfusion risk, gynecologic surgery, perioperative, predict, predictive model, preoperative testing

\section{Introduction}

In 2012, the American Congress of Obstetrics and Gynecology and 70 specialty societies joined the American Board of Internal Medicine Foundation Choosing Wisely program with the goal of advancing national dialogue on avoiding wasteful or unnecessary medical tests, treatments, and procedures. ${ }^{1}$ The group recommended against routinely ordering complete blood cell counts, basic or comprehensive metabolic panels, and coagulation tests in low-risk patients for 3 reasons: (1) these studies are typically normal before low-risk surgery, (2) abnormal results lead to a change in management in as few as $3 \%$ of patients, and (3) randomized trials

Cite this article as: Stanhiser J, Chagin K, Jelovsek JE. A model to predict risk of blood transfusion after gynecologic surgery. Am J Obstet Gynecol 2017; volume: x.ex-x.ex.

0002-9378/\$36.00

(C) 2017 Elsevier Inc. All rights reserved.

http://dx.doi.org/10.1016/j.ajog.2017.01.004 demonstrated no difference in intraoperative or postoperative patient outcomes when preoperative testing is performed. $^{2-7}$

Despite these efforts, gynecologists heuristically order routine preoperative laboratory testing in low- and high-risk patients before surgery even when many of these laboratory results are already present in the medical record. One major reason for this testing is to identify medically high-risk patients, optimize them before surgery, and lower their risk. Specifically, providers are concerned about risk of anemia and surgical blood loss along with the need for a possible transfusion. Transfusion carries significant uncommon risks including allergic reaction, fever, and-even more rare-acute immune hemolytic reaction, delayed hemolytic reaction, transfusion-associated circulatory overload, transfusion-related acute lung injury, and bloodborne infections. ${ }^{8}$ Blood transfusions are also correlated with adverse postoperative outcomes and their associated costs, including septic, wound, thromboembolic, and pulmonary complications; longer hospital stays; higher hospital charges; and patient death. $^{9-11}$

The average risk of transfusion is variable in gynecology and ranges from $0.01 \%$ for operative hysteroscopy, $2-5 \%$ for operative laparoscopy, $0.3-11 \%$ for hysterectomy, $21 \%$ for myomectomy, and up to $78 \%$ for cytoreductive surgery. ${ }^{12-18}$ However, the overall average risk of a woman requiring a blood transfusion after gynecologic surgery is low making routine testing a high-cost, low-value decision. Improving the accuracy of predicting a patient's specific risk requires the surgeon to incorporate known risk factors and crudely estimate whether the patient is lower, similar, or higher than these averages.

Prediction models can be useful when estimating a patient's risk is challenging. This can be due to the need to account for multiple risk factors or when clinical practice is highly variable, and may result in unnecessary testing or variability in treatment. For this reason, prediction 
models are being incorporated into care paths and clinical practice guidelines. An accurate model that could predict the probability of transfusion may facilitate efforts to reduce unnecessary testing in low-risk patients since low-value, frequently employed interventions such as preoperative testing represent significant unreimbursed cost to health systems and expose patients to harm. Such a model could also aid in identifying highrisk patients and facilitate more efficient use of blood management services potentially decreasing associated patient risks and costs of transfusion. ${ }^{19}$

The objectives of this study were to build and validate a model that accurately predicts the probability of transfusion given a set of baseline patient characteristics and risk factors of women undergoing gynecologic surgery in a multiinstitutional health system.

\section{Materials and Methods}

This was an institutional review board-approved, retrospective cohort analysis of women who underwent gynecologic surgery at 10 institutions in a single health system by 116 surgeons from Jan. 1, 2010, through June 30, 2014. Guidelines for the transparent reporting of a multivariable prediction model for individual prognosis or diagnosis statement were used in this study. ${ }^{20}$ Eligible patients were identified if they had gynecologic surgery through review of their Current Procedural Terminology codes during the study period. Patients who underwent obstetric surgical procedures were excluded. Data were extracted from the institution-wide electronic medical record and using an electronic blood utilization tool, Haemonetics IMPACT. ${ }^{21}$ The outcome of the model was defined as any patient identified as receiving $\geq 1 \mathrm{U}$ of packed red blood cells, cryoprecipitate, platelets, or plasma on the day of or within 30 days of their surgery date. Candidate predictors of blood transfusion were compiled from a literature review, expert opinion, and clinical judgment and collected from the electronic record. ${ }^{22-25}$

Once the data set was complete it was divided into a model training and test set. When an external validation data set

\section{TABLE 1 \\ Variability in rates of transfusion using common gynecologic surgery categories}

\begin{tabular}{lcc} 
Common gynecologic surgery categories $^{\mathrm{a}}$ & $\begin{array}{l}\text { Rate of } \\
\text { transfusion, } \%\end{array}$ & $\begin{array}{l}95 \% \text { Confidence } \\
\text { interval }\end{array}$ \\
\hline \begin{tabular}{l} 
Procedure \\
\hline Colpopexy
\end{tabular} & 1 & \\
\hline Ectopic & 2 & $0.57-2.13$ \\
\hline Hysterectomy & 4 & $0.56-6.62$ \\
\hline Myomectomy & 7 & $3.13-4.20$ \\
\hline Approach & & $4.44-10.3$ \\
\hline Hysteroscopy & 0 & \\
\hline Vaginal & 1 & $0.14-0.40$ \\
\hline Laparoscopy & 1 & $0.54-1.62$ \\
\hline Laparotomy & 9 & $0.68-1.73$ \\
\hline \begin{tabular}{l} 
Procedure for malignancy \\
\hline Overall average transfusion rate
\end{tabular} & $7.80-10.33$ \\
\hline $\begin{array}{l}\text { a Not mutually exclusive. } \\
\text { Stanhiser et al. Transfusion prediction model. Am J Obstet Gynecol 2017. }\end{array}$ \\
\hline
\end{tabular}

is unavailable to test a new model but an existing modeling data set is sufficiently large, as in this case, it is recommended to split by time and develop the model using data from one period and evaluate its performance from data from a future period. This method is stronger methodologically than randomly splitting a data set. ${ }^{20}$ However, there are no guidelines on how to choose the time cut points, so we arbitrarily chose to divide the total cohort into thirds by using twothirds to build and internally validate and one-third to temporally validate the model using patients who underwent surgery in a time period after the development cohort. The total cohort was split into a model training cohort of 12,219 surgeries performed from January 2010 through December 2012 and a separate validation cohort of 6100 surgeries performed from January 2013 through June 2014.

In all, 47 candidate risk factors were considered for fitting on the training data set (Supplemental Table). Missing values in risk factors were assessed for missing at random using methods described by Harrell $^{26}$ and multiple imputation using chained equations were used to calculate missing values. ${ }^{27}$
Imputed values were used for predictors in each model while the outcomes for all models were based only on actual and not imputed events.

A multiple logistic model was fit on the training cohort. Continuous variables were modeled by fitting 3 , 4 , and 5 knot-restricted cubic splines to avoid the assumption of a linear association between the continuous variable and the outcome. ${ }^{28}$ Categorical variables were not considered for model fitting when expected events were $<5$, when the SE was $>0.4$, or when collinearity was detected using a variable inflation factor that was $>10 .^{28}$ The variable selection process was done using Harrell et al's ${ }^{29}$ model approximation process of backward elimination to rank the variables in order of importance starting from the full model using a bootstrap biascorrected concordance index as the stopping criteria. This process started with the full model and removed each variable one at a time, while calculating the model's accuracy at the point of each variable removal. Each variable's removal was determined by the variable that produced the smallest reduction in the adjusted $R^{2}$. This was repeated until the accuracy's change was $<0.01$ 
resulting in the best parsimonious model.

Model performance was measured using the concordance index, calibration plots, and Brier score. The concordance index is a measurement of discrimination and measures the model's ability to assign a higher predicted probability to a patient who is at high risk and a lower predicted probability to a patient who is at low risk. The concordance index ranges from $0.5-1$, where 0.5 indicates that the model is no better than chance at making a prediction and 1 indicates that the model perfectly identifies those who experienced the event and those who did not. The calibration plot measures the relationship between the model's predicted probability and the actual probability. A perfect relationship will follow a straight 45 -degree line. The Brier score measures the overall accuracy of a model's predictions. ${ }^{30}$ The model was internally validated using 1000 bootstrap samples to produce bias-corrected estimates of the model's performance. This was followed by testing the model's performance on the separate test cohort. The final prediction model's relationship among the predictors was visualized using a nomogram and an online calculator was built for easy clinical use located at: http://riskcalc.org: 3838/.

A decision curve analysis is a form of decision analysis. A decision curve was plotted to inform clinicians about the range of threshold probabilities for which the prediction model would be of clinical value. ${ }^{31}$ Decision curve analysis offers insight into clinical consequences of using the model by determining the relationship between a chosen predicted probability threshold and the relative value of false-positive and false-negative results to obtain a value of net benefit of using the model at that threshold. ${ }^{32}$ All analyses were performed using $\mathrm{R}$ version 3.2.3 (R Foundation for Statistical Computing, Vienna, Austria).

\section{Results}

A total of 18,319 gynecologic surgeries occurred during the study period. The overall average rate of transfusion in the training cohort was 239 of 12,219

\section{TABLE 2}

Variables in model to predict risk of transfusion after gynecologic surgery

\begin{tabular}{|c|c|c|c|}
\hline & Adjusted odds ratio & $\begin{array}{l}\text { Lower } \\
95 \% \mathrm{Cl}\end{array}$ & $\begin{array}{l}\text { Upper } \\
95 \% \mathrm{Cl}\end{array}$ \\
\hline Intercept & 4.166 & -2.808 & 11.140 \\
\hline BMI & -0.158 & -0.454 & 0.138 \\
\hline $\mathrm{BMI}^{\mathrm{a}}$ & 3.867 & -7.852 & 15.586 \\
\hline $\mathrm{BMI}^{\mathrm{b}}$ & -4.988 & -17.089 & 7.114 \\
\hline Fibroids & -0.770 & -1.742 & 0.202 \\
\hline Heavy menstrual bleeding & -2.141 & -3.179 & -1.103 \\
\hline Hemoglobin, $\mathrm{g} / \mathrm{dL}$ & -0.996 & -1.184 & -0.809 \\
\hline History of laparotomy & -2.435 & -3.766 & -1.103 \\
\hline Hypertension & 1.634 & 0.816 & 2.451 \\
\hline Hysteroscopy & -3.933 & -5.522 & -2.345 \\
\hline Laparotomy & 4.824 & 3.815 & 5.832 \\
\hline Malignancy & 1.651 & 0.554 & 2.747 \\
\hline Myomectomy & 2.572 & 1.042 & 4.102 \\
\hline Ovarian cancer & 2.375 & 1.261 & 3.490 \\
\hline Parity & 2.118 & 0.438 & 3.798 \\
\hline Parity $^{\mathrm{a}}$ & -14.428 & -24.179 & -4.677 \\
\hline Parity ${ }^{b}$ & 39.671 & 10.766 & 68.577 \\
\hline Parity $^{\mathrm{c}}$ & -37.782 & -72.677 & -2.888 \\
\hline
\end{tabular}

Equation is available upon request for further research purposes by contacting authors.

$B M I$, body mass index; $C$ l, confidence interval.

${ }^{\text {a }}$ Nonlinear component $\mathrm{A}$ of the function describing the variable and the probability of transfusion; ${ }^{\mathrm{b}}$ Nonlinear component $\mathrm{B}$ of the function describing the variable and the probability of transfusion; ${ }^{\mathrm{C}}$ Nonlinear component $\mathrm{C}$ of the function describing parity and the probability of transfusion.

Stanhiser et al. Transfusion prediction model. Am J Obstet Gynecol 2017.
(2\%; 95\% confidence interval [CI], $1.72-2.22 \%)$ surgeries. Rates of transfusion grouped by common gynecologic procedures, common approaches used by gynecologic surgeons, or for malignancy only are compared to the overall average rate of transfusion in Table 1. As expected, hysterectomy and myomectomy had higher than average rates of transfusion (4\% and $7 \%$, respectively) and when procedures were performed for malignancy, this rate rose to an average of $16 \%$.

The unadjusted comparisons of the 47 candidate predictors in the training cohort are presented in the Supplemental Table. Among the candidate predictors, expected events were $<5$ in 3 categorical variables, the SE was $>0.4$ in 21 variables, and collinearity was detected in 1 variable leaving 22 candidate predictors considered. Body mass index (BMI) and parity had significant nonlinear associations with risk of transfusion (Supplemental Figures 1 and 2).

Twelve variables were included within the final model. Low hemoglobin, history of hypertension, history of ovarian cancer, and performing a laparotomy, myomectomy, or a procedure for malignancy increased the risk of blood transfusion. In contrast, history of fibroids, heavy menstrual bleeding, previous laparotomy, or performing a hysteroscopy were associated with a decreased risk of blood transfusion (Table 2). The nomogram illustrates the strength of association of the predictors to the outcome as well as the nonlinear associations between BMI and parity and risk of transfusion (Figure 1). 


$\begin{aligned} & \text { FIGURE } 1 \\ & \text { Nomogram for predicting probability of transfusion after gynecologic } \\ & \text { surgery }\end{aligned}$
Points

\begin{tabular}{|c|c|c|}
\hline & 40 & $60 \quad 80$ \\
\hline 1' & 30 & 20 \\
\hline Planning Laparotomy & & \\
\hline & FALSE & \\
\hline Planning myomectomy & & \\
\hline & FALSE & TRUE+ \\
\hline Planning Procedures $f$ & & \\
\hline possible malignancy & FALSE & TRUE+ \\
\hline Planning hysteroscopy & TRUE+ & \\
\hline History of Uterine Fibr & 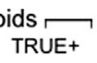 & \\
\hline History of Hypertensio & 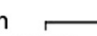 & \\
\hline & FALSE & TRUE+ \\
\hline History of Heavy & & \\
\hline Menstrual Bleeding & TRUE+ & FALSE \\
\hline History of Ovarian Car & Icer & $\overrightarrow{\text { TRUE+ }}$ \\
\hline Previous Laparotomy & 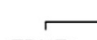 & $\longrightarrow$ \\
\hline & TRUE+ & FALSE \\
\hline Parity & 3 & $\pi+$ \\
\hline & 409 & 1 \\
\hline
\end{tabular}

Preop Hemoglobin $(\mathrm{g} / \mathrm{dL})$

$$
\begin{array}{lllllllllllllll}
20 & 19 & 18 & 17 & 16 & 15 & 14 & 13 & 12 & 11 & 10 & 9 & 8 & 7 & 6
\end{array}
$$

Total Points

Predicted Probability of Transfusion after Surgery

\begin{tabular}{llllllllllllll}
\hline 0 & 20 & 40 & 60 & 80 & 100 & 120 & 140 & 160 & 180 & 200 & 220 & 240 & 260
\end{tabular}

First row (points) is point assigned to each variable's measurement from rows 2-13, which are variables included in predictive model. Assigned points for all variables are then summed and total can be located on line 14 (total points). Once total points are located, draw vertical line down to bottom line to obtain predicted probability of transfusion. For parity predictor, following values should be read from left to right: (2 or 3), 4, 5, 6, 0, 7, 8, 9, 10, and 1 .

Stanhiser et al. Transfusion prediction model. Am J Obstet Gynecol 2017.

On internal validation, the final parsimonious model had excellent discrimination as demonstrated by a bias-corrected concordance index of 0.906 (95\% CI, 0.890-0.928) and a Brier score of 0.017 . On temporal validation, the model continued to have excellent discriminatory ability (concordance index, 0.915; 95\% CI, 0.872-0.954). Figure 2 demonstrates the calibration curve of the model's performance on the
(Figure 3). This suggests that basing decisions on the model will result in an overall net benefit compared to not using the model.

\section{Comment}

We have successfully built and temporally validated a model that accurately predicts a patient's risk of receiving blood transfusion after gynecologic surgery. The initial tests of the model's generalizability are promising as it was developed from a large cohort and tested in a subsequent cohort from multiple different institutions in a single health system by $>100$ different surgeons. The model had excellent discrimination ( $>90 \%$ accurate) between women at lower and higher risk and was able to maintain this accuracy across a large range of useful predicted probabilities (up to $40-50 \%$ risk). The model was accurate up to approximately $40-50 \%$ risk of transfusion, and then it began to slightly overpredict risk. We believe this slight overprediction, however, is unlikely to change a clinician's decision on management. Beyond accuracy, the model appears to be clinically valuable and likely to do more good than harm when used to make decisions when the predicted probability is between $0-50 \%$ as displayed by the decision curve. ${ }^{33}$

This study also has important secondary findings. We have determined overall average rates of blood transfusion in gynecologic surgery and rates of transfusion depending on different groupings of gynecologic surgery (Table 1). These average estimates are useful for policy makers, those responsible for allocating institutional resources, and those communicating with patients. This study also contributed to the existing body of literature investigating risk factors for transfusion in women undergoing surgery. Although many of these findings were expected to increase the risk of blood transfusion (eg, low hemoglobin, history of ovarian cancer, laparotomy, myomectomy, or a procedure for malignancy), we were also able to demonstrate interesting unadjusted nonlinear associations with BMI and parity that may need further investigation. At first glance, a history of 


\section{FIGURE 2}

\section{Calibration curve demonstrating transfusion model's performance when tested on validation cohort}

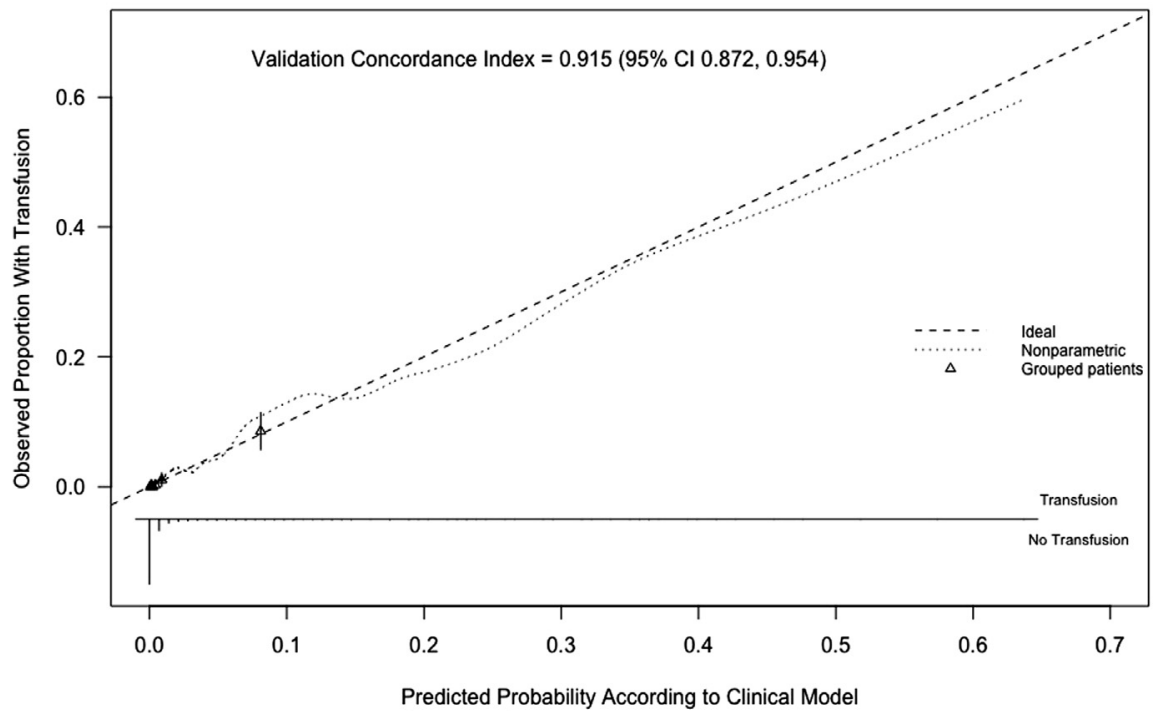

Calibration curve demonstrating transfusion model's performance when tested on validation cohort of women undergoing gynecologic surgery from January 2013 through June 2014.

$\mathrm{Cl}$, confidence interval.

Stanhiser et al. Transfusion prediction model. Am J Obstet Gynecol 2017.

fibroids, heavy menstrual bleeding, or a previous laparotomy were surprisingly associated with a decreased risk of blood transfusion. However, it is possible that

these factors are routinely recognized during clinical care allowing surgeons to intervene prior to or during surgery and potentially reduce risk when all other

\section{FIGURE 3}

\section{Decision curve for transfusion after gynecologic surgery decision model}

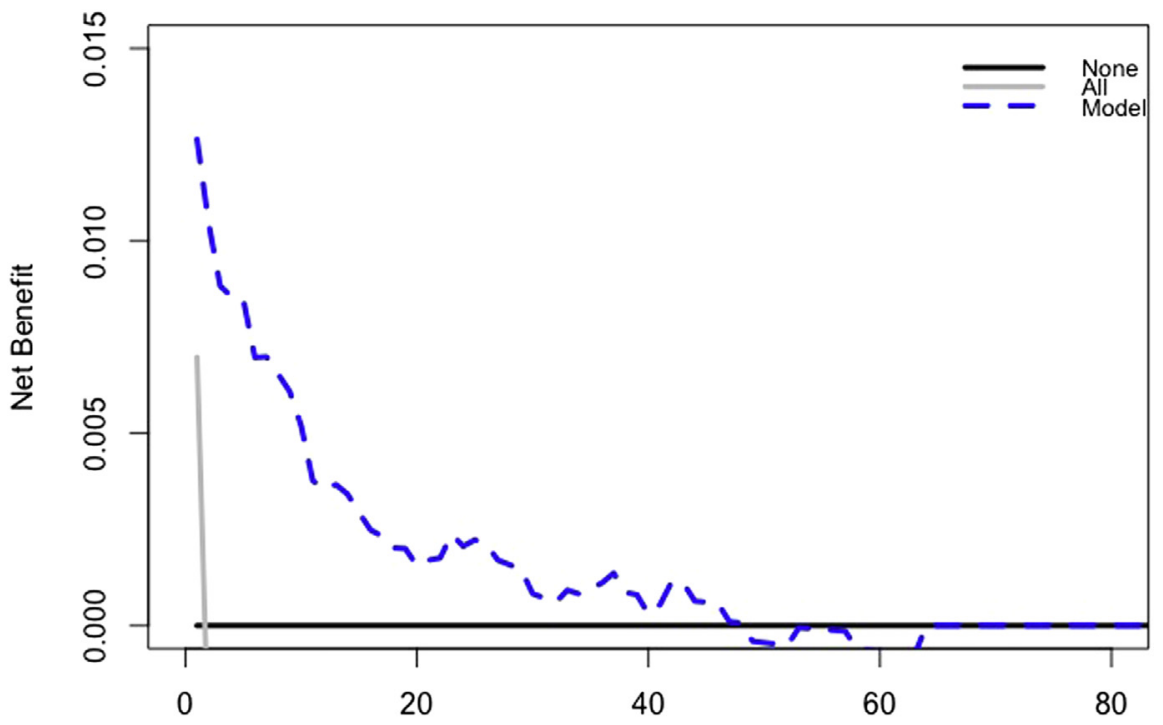

Threshold Probability (\%)

Stanhiser et al. Transfusion prediction model. Am J Obstet Gynecol 2017. risk factors are considered in the model. It is for this reason we suggest using caution in generalizing the identified variables in the model to cause-effect relationships rather than factors that predict transfusion.

Our findings are comparable to previous studies. Prediction models for blood transfusion in other specialties have found predictors to include older age, lower BMI, and lower preoperative hemoglobin, as well as specialty-specific factors. ${ }^{22-26}$ The gynecologic literature supports increased risk of transfusion with lower hemoglobin, malignancy, and performing laparotomy or myomectomy, as our study reports. However, it is difficult to determine an overall rate of transfusion from existing literature. Although the risks of procedurespecific transfusion have been reported, these studies are limited by comparatively low sample size reducing the ability to identify important risk factors particularly in low-risk surgical procedures.

The strengths of this study are use of a large cohort of women undergoing a variety of gynecologic surgeries by different gynecologic surgeons across multiple institutions within a health care system to build and temporally validate a highly accurate model and the use of advanced predictive analytic techniques that follow recent reporting guidelines. A further strength is that the predictors included within the model are welldefined clinical factors that are routinely known preoperatively and easily collected in practice, as well as the availability of an easy-to-use online calculator. This increases the model's potential ease of use.

This study has several significant limitations. Just as clinical trials or cohorts followed from a single institution need to be further tested in other centers, our model's ability to accurately perform using data from different health care systems across wide geographic areas is unknown. Although we believe the relatively large number and variety of procedures, institutions, and surgeons included within this study likely supports the model's early use, it should be further tested in diverse populations 
with a variety of care practices. Additionally, the model is not perfect and the predictions are slightly overestimated when $>40 \%$. This likely results from the relatively few patients whose risk is actually greater than this threshold reducing the model fit at this extreme.

There are several opportunities to innovatively use this type of model. By integrating the model into the electronic record it affords a chance to automate electronic decision support around preoperative planning and blood management. The model is especially useful in patients who have any preexisting hemoglobin value in their medical record. If the model identifies patients at low risk of transfusion this may automatically question the need to order a type and screen, type and cross, or potentially unnecessary repeat testing such as a complete blood cell count or further preoperative laboratory testing overall. This model may therefore be a valuable tool within our specialty to further the Choosing Wisely program's campaign to avoid wasteful and unnecessary medical tests. In our institution, reducing unnecessary testing in patients at low risk for blood transfusion is estimated to save the institution approximately $\$ 77,000$ per 1000 gynecologic surgeries. Alternatively, identifying patients at high risk for transfusion may improve efficiency of perioperative blood management and reduce transfusions. The costs associated with transfusing a single unit of blood are significant and do not include the cost of treating any adverse associations of transfusion or the associated increased length of hospital stay. These costs far outweigh the lower cost of oral treatments of anemia, intravenous iron therapy, and cell salvage utilization. We suspect that for each transfusion avoided, the patient and financial benefit may be significant due to the large number of patients undergoing gynecologic surgery. Future investigations should include measuring the model's impact on patient and cost outcomes.

Overall, our new model accurately predicts risk of transfusion after gynecologic surgery in early testing of a multiinstitutional health system. Identification of patients at low risk for transfusion may eliminate further unnecessary preoperative testing in patients with existing preoperative hemoglobin levels. Identification of patients at high risk for transfusion may allow improved perioperative blood management utilization potentially reducing transfusions and their associated risks and costs.

\section{References}

1. Choosing wisely An initiative of the $A B I M$ Foundation. Available at: http://www. choosingwisely.org/. Accessed May 2, 2016.

2. Monro J, Booth A, Nicholl J. Routine preoperative testing: a systematic review of the evidence. Health Technol Assess 1997;1: 1-62.

3. Smetana GW, Macphearson DS. The case against routine preoperative laboratory testing. Med Clin North Am 2003;87:7-40.

4. Bryson GL, Wyand A, Bragg PR. Preoperative testing is inconsistent with published guidelines and rarely changes management. Can J Anaesth 2006;53:236-41.

5. Narr BJ, Hansen TR, Warner MA. Preoperative laboratory screening in healthy Mayo patients: cost-effective elimination of test and unchanged outcomes. Mayo Clin Proc 1991;66: 155-9.

6. Keay L, Lindsley K, Tielsch J, Katz J, Schein $\mathrm{O}$. Routine preoperative medical testing for cataract surgery. Cochrane Database Syst Rev 2012;3:CD007293.

7. Chung F, Yuan H, Yin L, Vairavanathan S, Wong DT. Elimination of preoperative testing in ambulatory surgery. Anesth Analg 2009;108: 467-75.

8. Indian J. Adverse events related to blood transfusion. J Anaesth 2014;58:543-51.

9. Glance LG, Dick AW, Mukamel DB, et al. Association between intraoperative blood transfusion and mortality and morbidity in patients undergoing noncardiac surgery. Anesthesiology 2011;114:283-92.

10. Abdelsattar ZM, Hendren S, Wong SL, Campbell DA Jr, Henk P. Variation in transfusion practice and the effect on outcomes after noncardiac surgery. Ann Surg 2015;262: $1-6$.

11. Vamvakas EC, Carven JH. Allogenic blood transfusion, hospital charges, and length of hospitalization: a study of 487 consecutive patients undergoing colorectal cancer resection. Arch Pathol Lab Med 1998;122:145-51.

12. Propst AM, Liberman RF, Harlow BL, Ginsburg ES. Complications of hysteroscopic surgery: predicting patients at risk. Obstet Gynecol 2000;96:517-20.
13. Mirhashemi R, Harlow BL, Ginsburg ES, Signorello LB, Berkowitz R, Feldman S. Predicting risk of complications with gynecologic laparoscopic surgery. Obstet Gynecol 1998;92: 327-31.

14. Ekeroma AJ, Ansari A, Stirrat GM. Blood transfusion in obstetrics and gynecology. BJOG 1997;104:278-84.

15. Otton GR, Mandapati S, Streatfeild KA, Hewson AD. Transfusion rates associated with hysterectomy for benign disease. Aust N Z J Obstet Gynaecol 2001;41:439-42.

16. Thoestesen LM, Rasmussen $\mathrm{KL}$, Lauszus FF, Hansen CT, Titlestad KE, Larsen R. Transfusion rate and prevalence of unexpected red blood cell alloantibodies in women undergoing hysterectomy for benign disease. Acta Obstet Gynecol Scand 2011;90: 636-41.

17. LaMorte A, Lalwani S, Diamond M. Morbidity associated with abdominal myomectomy. Obstet Gynecol 1993;82:897-900.

18. Penman-Aguilar A, Whiteman MK, Cox S, et al. Complications of common gynecologic surgeries among HIV-infected women in the United States. Infect Dis Obstet Gynecol 2012;2012:610876.

19. Goodnough LT, Shander A. Patient blood management. Anesthesiology 2012;116: 1367-76.

20. Collins GS, Reitsma JB, Altman DG, Moons KG. Transparent reporting of a multivariable prediction model for individual prognosis or diagnosis (TRIPOD): the TRIPOD statement. Ann Intern Med 2015;162:55-63.

21. Haemonetics Corporation. Haemonetics: the blood management company: IMPACT Online. Available at: http://www.haemonetics. com/Products/Services/Consulting-Services/ IMPACT-Online.aspx. Accessed May 3, 2016. 22. Goudi R, Sterne JAC, Verheyden V, Bhabra M, Ranucci M, Murphy GJ. Risk scores to facilitate preoperative prediction of transfusion and large volume blood transfusion associated with adult cardiac surgery. $\mathrm{Br} J$ Anaesth 2015;114:757-66.

23. Kane S, Collins S, Sproat L, Mangel J. Predictors of transfusion requirement among patients who undergo hysterectomy for benign disease. J Gynecol Surg 2012;28: 108-12.

24. Wang $H-Q$, Yang J, Yang J-Y, Wang $W-T$, Yan L-N. Development and validation of a predictive score for perioperative transfusion in patients with hepatocellular carcinoma undergoing liver resection. Hepatobiliary Pancreat Dis Int 2015;14: 394-400.

25. Ahmed I, Chan J, Jenkins P, Brenkel I, Walsmsley P. Estimating the transfusion risk following total knee arthroplasty. Orthopedics 2012;35:e1465-71.

26. Harrell FE. Regression modeling strategies: with application to linear models, logistic regression, and survival analysis. New York: Springer; 2015. 
27. van Burren S, Groothuis-Oudshoorn K MICE: multivariate imputation by chained equations in R. J Stat Software 2011;45(3).

28. Kutner MH, Nachtsheim CJ, Neter J. Applied linear regression models. New York: McGraw-Hill Irwin; 2004.

29. Harrell FE Jr, Lee KL, Mark DB. Multivariable prognostic models: issues in developing models, evaluating assumptions. Stat Med 1996;15:361-87.

30. Rufibach K. Use of Brier score to assess binary predictions. J Clin Epidemiol 2010;63:938-9.
31. Vickers AJ. Decision analysis for the evaluation of diagnostic tests, prediction models and molecular markers. Am Stat 2008;62: 314-20.

32. Van Calster B, Vickers AJ. Calibration of risk prediction models: impact on decision-analytic performance. Med Decis Making 2015;35: 162-9.

33. Vickers AJ, Van Calster B, Steyerberg EW. Net benefit approaches to the evaluation of prediction models, molecular markers, and diagnostic tests. BMJ 2016;352:i6.

\section{Author and article information}

From the Obstetrics, Gynecology, and Women's Health Institute (Drs Stanhiser and Jelovsek) and Quantitative Health Sciences (Mr Chagin), Cleveland Clinic, Cleveland, $\mathrm{OH}$.

Received Oct. 26, 2016; revised Jan. 1, 2017; accepted Jan. 9, 2017.

The authors report no conflict of interest.

Corresponding author: Jamie Stanhiser, MD. jamiestanhiser@gmail.com 


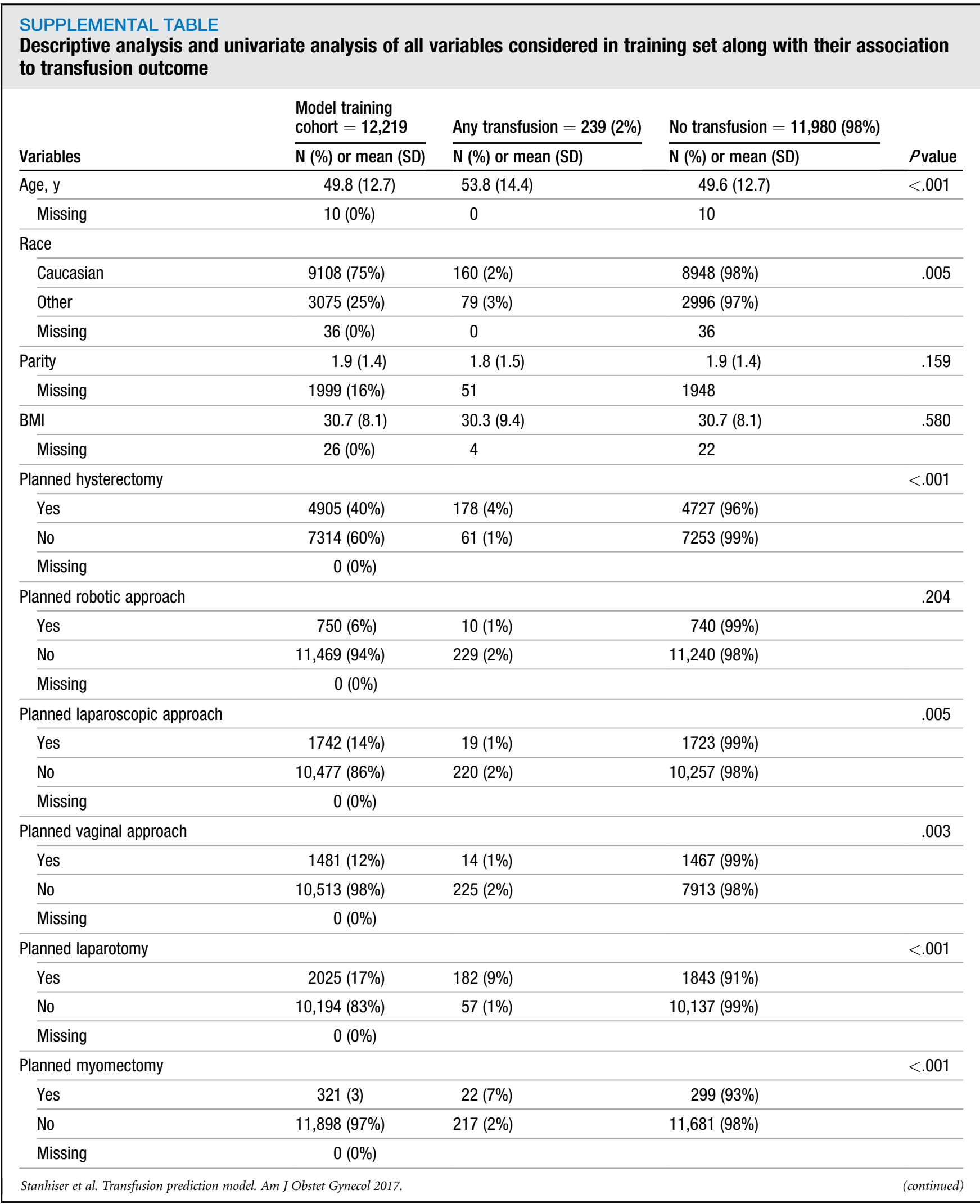




\begin{tabular}{|c|c|c|c|c|}
\hline & $\begin{array}{l}\text { Model training } \\
\text { cohort }=12,219\end{array}$ & Any transfusion $=239(2 \%)$ & No transfusion $=11,980(98 \%)$ & \\
\hline Variables & $\mathrm{N}(\%)$ or mean (SD) & $\mathrm{N}(\%)$ or mean (SD) & $\mathrm{N}(\%)$ or mean (SD) & $P$ value \\
\hline Planned colpopexy & & & & .063 \\
\hline Yes & $890(7 \%)$ & $10(1 \%)$ & $880(99 \%)$ & \\
\hline No & $11,329(93 \%)$ & $229(2 \%)$ & $11,100(98 \%)$ & \\
\hline Missing & $0(0 \%)$ & & & \\
\hline $\begin{array}{l}\text { Gynecology oncology procedure, } \\
\text { ie, nodes, radical, omentectomy }\end{array}$ & & & & $<.001$ \\
\hline Yes & $454(4 \%)$ & $3(3 \%)$ & $137(98 \%)$ & \\
\hline No & $11,765(96 \%)$ & $236(2 \%)$ & $11,843(98 \%)$ & \\
\hline Missing & $0(0 \%)$ & & & \\
\hline Planned surgery for ectopic & & & & .755 \\
\hline Yes & $140(1 \%)$ & $3(3 \%)$ & $108(97 \%)$ & \\
\hline No & $12,079(99 \%)$ & $183(2 \%)$ & $8878(98 \%)$ & \\
\hline Missing & $0(0 \%)$ & & & \\
\hline Planned hysteroscopy & & & & $<.001$ \\
\hline Yes & $6263(51 \%)$ & $15(0 \%)$ & $6248(100 \%)$ & \\
\hline No & $5956(49 \%)$ & $224(4 \%)$ & $5732(96 \%)$ & \\
\hline Missing & $0(0 \%)$ & & & \\
\hline Preoperative hemoglobin, g/dL & $12.6(1.7)$ & $11.1(1.9)$ & $12.6(1.7)$ & $<.001$ \\
\hline Missing & $6620(54 \%)$ & 131 & 6489 & \\
\hline Preoperative platelets, $\times 10^{9} / \mathrm{L}$ & $284(80)$ & $326(141)$ & $283(78)$ & .003 \\
\hline Missing & $6642(54 \%)$ & 133 & 6509 & \\
\hline Any radiation history & & & & .548 \\
\hline Yes & $154(1 \%)$ & $4(2 \%)$ & $235(98 \%)$ & \\
\hline No & 12,065 (99\%) & $150(1 \%)$ & $11,830(99 \%)$ & \\
\hline Missing & $0(0 \%)$ & & & \\
\hline Abortion history & & & & .269 \\
\hline Yes & $175(1 \%)$ & $1(1 \%)$ & $174(99 \%)$ & \\
\hline No & 12,044 (99\%) & $238(2 \%)$ & $11,806(98 \%)$ & \\
\hline Missing & $0(0 \%)$ & & & \\
\hline Anemia history & & & & $<.001$ \\
\hline Yes & $2157(18 \%)$ & $70(3 \%)$ & $2087(97 \%)$ & \\
\hline No & $10,062(82 \%)$ & $169(2 \%)$ & $9893(98 \%)$ & \\
\hline Missing & $0(0 \%)$ & & & \\
\hline Carcinomatosis history & & & & $<.001$ \\
\hline Yes & $53(0 \%)$ & $12(23 \%)$ & $41(77 \%)$ & \\
\hline No & $12,166(100 \%)$ & $227(2 \%)$ & 11,939 (98\%) & \\
\hline Missing & $0(0 \%)$ & & & \\
\hline
\end{tabular}




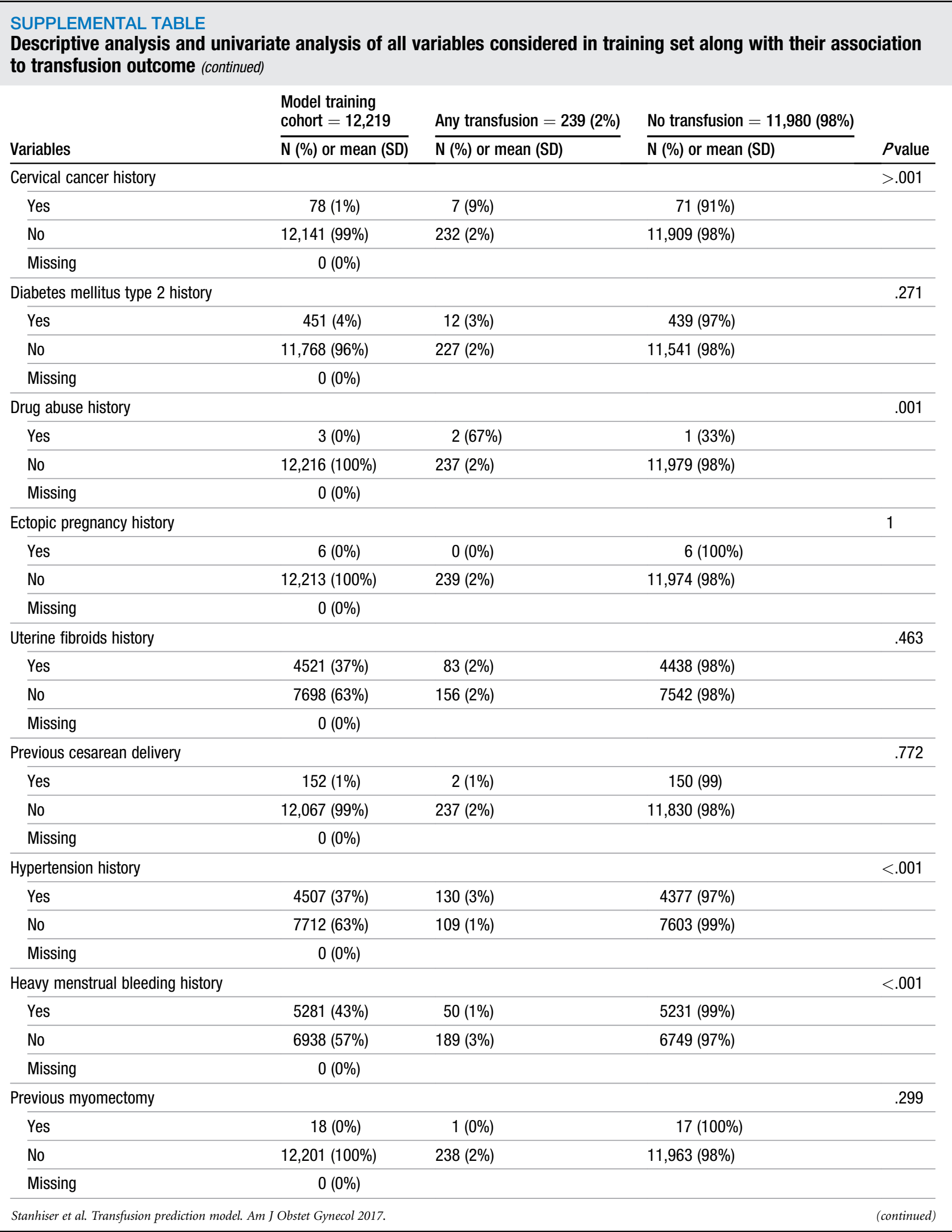




\begin{tabular}{|c|c|c|c|c|}
\hline & $\begin{array}{l}\text { Model training } \\
\text { cohort }=12,219\end{array}$ & Any transfusion $=239(2 \%)$ & No transfusion = 11,980 $(98 \%)$ & \\
\hline Variables & $\mathrm{N}(\%)$ or mean (SD) & $\mathrm{N}(\%)$ or mean (SD) & $\mathrm{N}(\%)$ or mean (SD) & $P$ value \\
\hline Ovarian cancer & & & & $<.001$ \\
\hline Yes & $449(4 \%)$ & $74(17 \%)$ & $375(83 \%)$ & \\
\hline No & $11,770(96 \%)$ & $165(1 \%)$ & $11,605(99 \%)$ & \\
\hline Missing & $0(0 \%)$ & & & \\
\hline Systemic lupus erythematosus & & & & 283 \\
\hline Yes & $111(1 \%)$ & $0(0 \%)$ & $111(100 \%)$ & \\
\hline No & $12,108(99 \%)$ & $239(2 \%)$ & $11,869(98 \%)$ & \\
\hline Missing & $0(0 \%)$ & & & \\
\hline Smoking history & & & & 110 \\
\hline Yes & $29(0 \%)$ & $2(7 \%)$ & 27 (93\%) & \\
\hline No & $12,190(100 \%)$ & $237(2 \%)$ & $11,953(98 \%)$ & \\
\hline Missing & $0(0 \%)$ & & & \\
\hline Uterine cancer history & & & & $<.001$ \\
\hline Yes & $381(3 \%)$ & $32(8 \%)$ & $349(92 \%)$ & \\
\hline No & $11,838(97 \%)$ & $207(2 \%)$ & $11,631(98 \%)$ & \\
\hline Missing & $0(0 \%)$ & & & \\
\hline Vulvar cancer history & & & & 257 \\
\hline Yes & $15(0 \%)$ & $1(7 \%)$ & $14(93 \%)$ & \\
\hline No & $12,204(100 \%)$ & $238(2 \%)$ & $11,966(98 \%)$ & \\
\hline Missing & $0(0 \%)$ & & & \\
\hline Previous dilation and curettage & & & & $<.001$ \\
\hline Yes & $976(8 \%)$ & $4(0 \%)$ & $972(100 \%)$ & \\
\hline No & $11,243(92 \%)$ & $235(2 \%)$ & $11,008(98 \%)$ & \\
\hline Missing & $0(0 \%)$ & & & \\
\hline Previous dilation and evacuation & & & & 1 \\
\hline Yes & $2(0 \%)$ & $0(0 \%)$ & $2(100 \%)$ & \\
\hline No & $12,217(100 \%)$ & $239(2 \%)$ & $11,978(98 \%)$ & \\
\hline Missing & $0(0 \%)$ & & & \\
\hline $\begin{array}{l}\text { Previous laparoscopy for } \\
\text { ectopic pregnancy }\end{array}$ & & & & .761 \\
\hline Yes & $144(1 \%)$ & $3(2 \%)$ & $141(98 \%)$ & \\
\hline No & $12,075(99 \%)$ & $236(2 \%)$ & $11,839(98 \%)$ & \\
\hline \multicolumn{5}{|l|}{ Missing } \\
\hline Previous exploratory laparotomy & & & & $<.001$ \\
\hline Yes & $525(4 \%)$ & $24(5 \%)$ & $501(95 \%)$ & \\
\hline No & $11,694(96 \%)$ & $215(2 \%)$ & $11,479(98 \%)$ & \\
\hline Missing & $0(0 \%)$ & & & \\
\hline
\end{tabular}




\begin{tabular}{|c|c|c|c|c|}
\hline & $\begin{array}{l}\text { Model training } \\
\text { cohort = 12,219 }\end{array}$ & Any transfusion $=239(2 \%)$ & No transfusion $=11,980(98 \%)$ & \\
\hline Variables & $\mathrm{N}(\%)$ or mean (SD) & $\mathrm{N}(\%)$ or mean (SD) & $\mathrm{N}(\%)$ or mean (SD) & $P$ value \\
\hline $\begin{array}{l}\text { Previous total abdominal } \\
\text { hysterectomy }\end{array}$ & & & & $<.001$ \\
\hline Yes & $1426(12 \%)$ & $80(6 \%)$ & $1346(94 \%)$ & \\
\hline No & $10,793(88 \%)$ & $159(2 \%)$ & $10,634(98 \%)$ & \\
\hline Missing & $0(0 \%)$ & & & \\
\hline $\begin{array}{l}\text { Previous total laparoscopy } \\
\text { hysterectomy }\end{array}$ & & & & .002 \\
\hline Yes & $465(4 \%)$ & $1(0 \%)$ & $464(100 \%)$ & \\
\hline No & $11,754(96 \%)$ & $238(2 \%)$ & $11,516(98 \%)$ & \\
\hline Missing & $0(0 \%)$ & & & \\
\hline Previous total vaginal hysterectomy & & & & .005 \\
\hline Yes & $1283(11 \%)$ & $12(1 \%)$ & $1271(99 \%)$ & \\
\hline No & $10,936(89 \%)$ & $227(2 \%)$ & $10,709(98 \%)$ & \\
\hline Missing & $0(0 \%)$ & & & \\
\hline Previous debulking surgery & & & & $<.001$ \\
\hline Yes & $39(0 \%)$ & $11(28 \%)$ & $28(72 \%)$ & \\
\hline No & $12,180(100 \%)$ & $228(2 \%)$ & $11,952(98 \%)$ & \\
\hline Missing & $0(0 \%)$ & & & \\
\hline Previous radical hysterectomy & & & & $<.001$ \\
\hline Yes & $294(2 \%)$ & $27(9 \%)$ & $267(91 \%)$ & \\
\hline No & $11,925(98 \%)$ & $212(2 \%)$ & $11,713(98 \%)$ & \\
\hline Missing & $0(0 \%)$ & & & \\
\hline Previous sacral colpopexy & & & & .532 \\
\hline Yes & $308(3 \%)$ & $4(1 \%)$ & $304(99 \%)$ & \\
\hline No & $11,911(97 \%)$ & $235(2 \%)$ & $11,676(98 \%)$ & \\
\hline Missing & $0(0 \%)$ & & & \\
\hline Previous uterine colpopexy & & & & .030 \\
\hline Yes & $701(6 \%)$ & $6(1 \%)$ & $695(99 \%)$ & \\
\hline No & $11,518(94 \%)$ & $233(2 \%)$ & $11,285(98 \%)$ & \\
\hline Missing & $0(0 \%)$ & & & \\
\hline $\begin{array}{l}\text { Anticoagulant use within } \pm 72 \mathrm{~h} \\
\text { of surgery }\end{array}$ & & & & $<.001$ \\
\hline Yes & $20(0 \%)$ & $4(20 \%)$ & $16(80 \%)$ & \\
\hline No & $12,199(100 \%)$ & $235(2 \%)$ & $11,964(98 \%)$ & \\
\hline Missing & $0(\%)$ & & & \\
\hline
\end{tabular}




\section{SUPPLEMENTAL FIGURE 1}

\section{Estimated spline transformation of body mass index and transfusion risk}

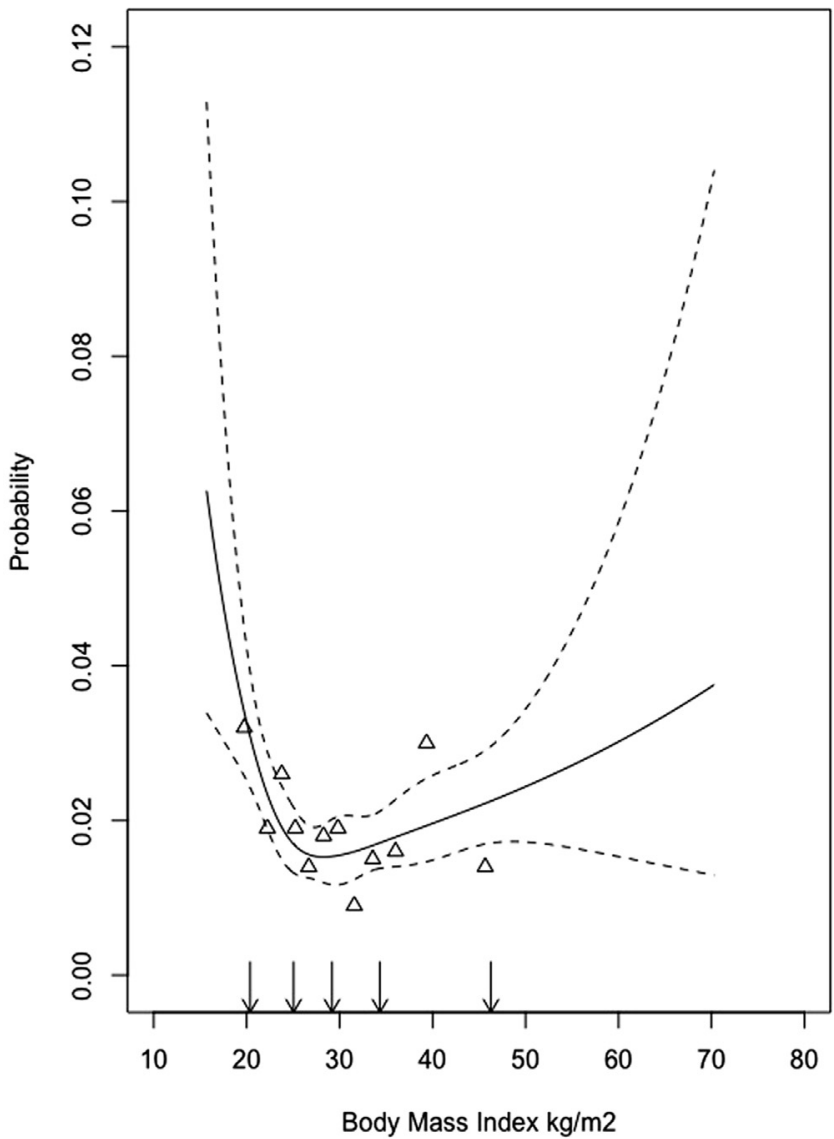

Predictions with group size of 1000 patients (triangles) and location of knot (arrows).

Stanhiser et al. Transfusion prediction model. Am J Obstet Gynecol 2017. 


\section{SUPPLEMENTAL FIGURE 2}

\section{Estimated spline transformation of parity and transfusion risk}

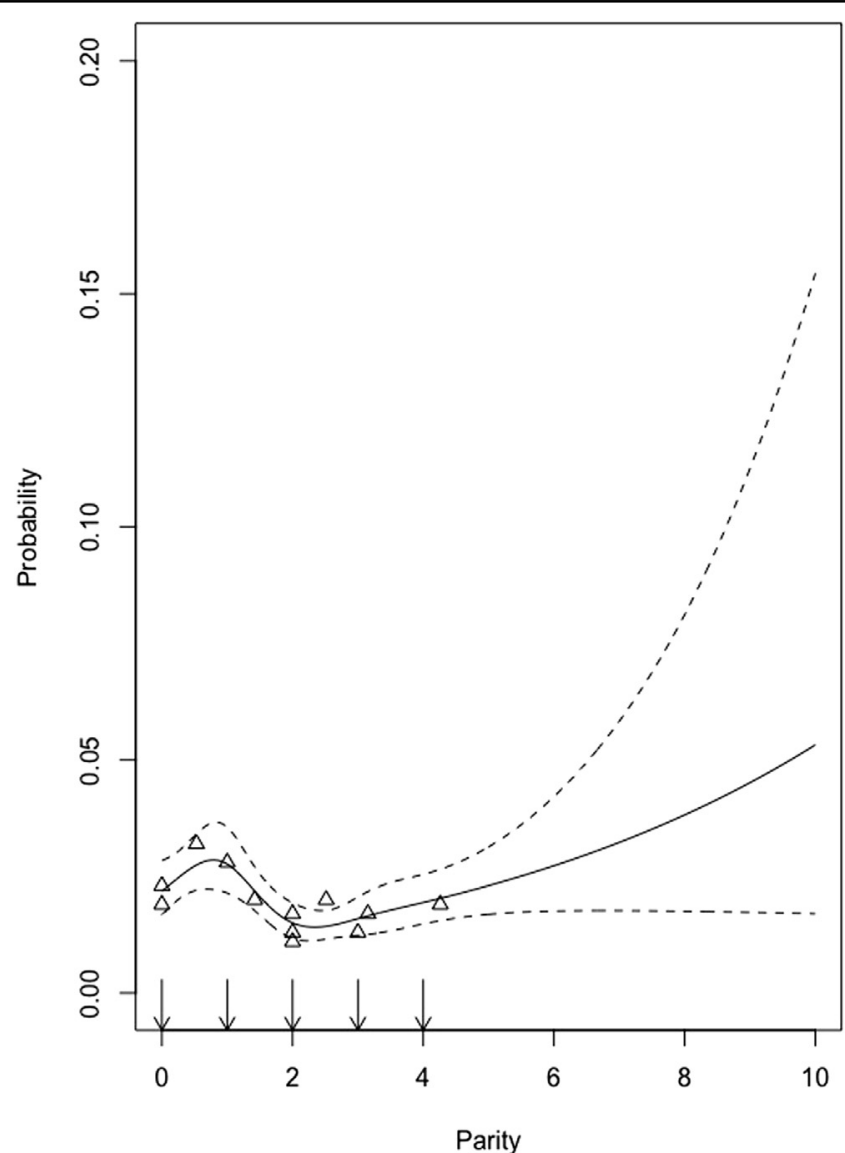

Predictions with group size of 1000 patients (triangles) and location of knot (arrows).

Stanhiser et al. Transfusion prediction model. Am J Obstet Gynecol 2017. 